\title{
Reseña
}

\section{Números públicos: Las estadísticas en Argentina (1990 - 2010) Claudia Daniel}

Primera edición. Buenos Aires, Fondo de Cultura Económica, 2013. 304 págs. ISBN 978-950-557-987-7

Sebastián Cruz Barbosa

Departamento de Planificación y

Políticas Públicas, UNLa.
Hay una cualidad central que destaca al libro de Claudia Daniel que es que permite al lector resituarse en relación a la frialdad de los números y datos de las estadísticas. Se trata, sin más, de la propia caracterización que se propone con el abordaje de los “números públicos” en un plano de significación política y cultural en la actualidad nacional argentina. ¿Qué significa pensar los números públicos en términos de significación social? ¿Cómo conceptualizar los resultados estadísticos en tanto objetos culturales? Las respuestas a estas interrogantes se van delineando a lo largo del libro, descartando en todo momento el abordaje formal de la estadística para dar paso a una mirada representacional en la que se reflexiona cómo se trazan puentes entre la instrumentalización de la estadística por vía de la política y las representaciones sociales como prismas para entender la realidad cotidiana.

La obra hace explícita una epistemología que apunta a producir una re-significación cultural y política de las estadísticas en la Argentina actual con el objetivo de desmontar sus presupuestos implícitos como evidencias cristalinas e imposibles de ser cuestionadas. El hecho de que los resultados estadísticos públicos se perfilen como fuente de dis- 
puta por el sentido, tanto social como político, como así también técnico y periodístico, hace de este objeto un "diamante semiótico" valorable para discurrir sobre él como campo de disputa por su forma de representación social. Los números públicos constituyen una parte del universo de las estadísticas y son presentados bajo cifras, porcentajes, indicadores, promedios, índices. Sin embargo, el enfoque que la autora nos invita a reflexionar consiste en cómo todos estos distintos modos científicos de reflejar las estadísticas son representados y se transforman en teorías del sentido común, categorías del pensamiento cotidiano de diversos actores de la realidad social construida por esos mismos sentidos.

En el análisis del “Índice de Riesgo País” la autora observa cómo él mismo comenzó en determinado momento a ser parte de una forma de representación del sentido común que trazaba puentes interpretativos entre narrativas de la crisis, al mismo tiempo que se configuraba la crisis como tal. Una audiencia del sentido común alejada del propio mercado financiero acortaba distancias con ese mundo distante en la medida en que sus percepciones eran vividas como el destino colectivo del país. La instalación del "Riesgo País” en la esfera pública argentina encontró, según la autora, su naturalización, a partir de un proceso de aceleración de la comunicación pública proveniente de lenguajes especializados desde el gobierno y los medios masivos de comunicación. Además, un conjunto de condiciones sociales y económicas críticas, tanto en el orden interno como internacional, contribuyeron a crear las condiciones históricas de la posibilidad representacional del índice, generando una "cultura de la medición".

¿Cuándo es posible afirmar que el lenguaje de los números “ancló” en la realidad Argentina de los años 90? Efectivamente, cuando ese lenguaje performó en la construcción representacional de la crisis llegando a generar efectos sociales y políticos concretos. Ese saber especializado de las finanzas, distante y cerrado hacia fines del 2000, permeó la vida del "día a día" de los ciudadanos argentinos en donde el riesgo país pasó a integrar un sistema de pensamiento de la vida cotidiana, comenzó a ser aludido constantemente, sin saber con certeza el grado de conocimiento específico sobre él. Una firma privada especializada en negocios financieros reemplazó al Estado como formador de sentidos, categorías del pensamiento social, en un contexto en el cual la economía se encontraba en crisis y el Estado estaba ausente. Para la autora, la Alianza había basado gran parte de su agencia en bajar el riesgo país y paulatinamente éste fue erosionando al elenco gubernamental a partir de la capacidad del índice en disciplinar, no sólo socialmente, sino también, a la propia clase política. Así, el índice de riesgo país operó como una suerte de somnífero para obturar alternativas de salida a la crisis.

Bajo una misma línea de análisis representacional como el desplegado para el caso del riesgo país, en el análisis de los "Márgenes de error estadístico" vuelve a surgir la pregunta por su inscripción en la realidad cotidiana. En ese sentido, se trata de observar 
el puente que va de la técnica a la significación social de la misma. De esta manera, se aproxima a la presentación del "margen de error" en el marco de una genealogía que abarca, desde la aparición de las encuestas de opinión pública asociadas a los principios democráticos y a las libertades individuales, pasando por su expansión como herramienta práctica de los políticos, hasta su desprestigio y opacidad como producto de las críticas sociales y de los expertos.

La autora indica que en el transcurso de la presidencia de Raúl Alfonsín se había creado una Secretaría de Información tendiente a proveer información del "estado de la opinión pública al gobierno”. Si bien la cartera no era de las más importantes en términos presupuestarios, permitía mostrar el grado de relevancia que comenzaban a tener las mediciones de las opiniones de la ciudadanía respecto de las cuestiones y problemas de interés público. Sin embargo, hacia los años 90 esa centralidad estatal de la política se vio desplazada hacia los medios de comunicación y la personalización política. En el marco de la transformación de la relación entre sociedad y política, el marketing político y los medios de comunicación reemplazaron a la democracia de los partidos políticos. La figura de un nuevo tipo de ciudadano "independiente" parecía desplegarse bajo el lema de la mayor reflexividad y autonomía, al mismo que tiempo que, se lo postulaba por fuera de las "arcaicas" identidades colectivas e ideologías.

Resulta muy interesante cómo se muestra la imbricación entre una sociedad "políticamente volátil" con cada vez menos compromiso político, con la necesidad creciente de medir. Las encuestas políticas se demandaban porque había cada vez más actores en la disputa política y porque se demandaba cada vez más su uso. La crisis del 2001 en Argentina no estuvo exenta de esa demanda creciente. Se señala con acierto que, si bien no existen estudios que demuestren el grado de influencia de las encuestas en las preferencias sociales y políticas de la gente, la propia valoración de la capacidad de influencia en la opinión pública reside en la creencia en la utilidad que tienen en términos estratégicos. Efectivamente, esa creencia es una herramienta simbólica para que los candidatos se posicionen en el espacio público. La utilidad de esos números, el llamado "efecto de opinión" dependerá de cómo el político los utilice a su favor.

Por otro lado, los especialistas en opinión pública se habían ganado el lugar de los portavoces de la "gente", un verdadero significante ambiguo. A pesar de ello las relaciones cruzadas entre medios, especialistas y empresas, sumados a los malos resultados terminaron generando desconfianza en los sondeos de opinión. Según la autora, en los últimos años la desconfianza en los números públicos ha llevado a los consultores a controlar exclusivamente la producción e interpretación de los datos. El debate por la regulación de este trabajo y el de su difusión generaron avances en el campo de su profesionalización, mientras que, las críticas éticas a su manipulación política o falsificación muestran que ese avance fue y es dispar. 
La pregunta por el qué sucede ante la disfuncionalidad de un índice (el Índice de Precios al Consumidor en este caso) es abordada contextualizando la historia compleja de este índice desde las primeras mediciones de Alejandro Bunge en 1918 hasta la actualidad del gobierno kirchnerista. El sistema público de estadísticas sufrió una lenta corrosión a lo largo de su historia en Argentina. Pero específicamente esa erosión del INDEC estuvo asociada a los gobiernos que las cuestionaron (desde el índice paralelo de Martínez de Hoz que no contemplaba la carne, las denuncias de "mentirosos" que propinaba el entonces Ministro de Economía Domingo Cavallo al Índice de Desocupación, hasta las críticas por irregularidad en la confección del IPC del gobierno kirchnerista) a las difusiones de mediciones alternativas respaldadas por consultoras privadas, la prensa nacional y extranjera, las universidades, entidades de consumidores y las agrupaciones políticas diversas.

Efectivamente los cuestionamientos a las estadísticas, como se señala en el libro, están fuertemente atravesados por la disputa por el sentido, y en ese marco, por la propia disputa política. Es por ello que, la autora informa con razón, la puja actual entre las consultoras privadas y el gobierno kirchnerista por hegemonizar el sentido de los números públicos. Refleja de esa manera, el desplazamiento que produjo el gobierno a los centros privados que habían participado, incluso, en cargos públicos en la década de los 90 instalando y desplegando sus políticas públicas de corte neoliberal.

La controversia en relación al índice de precios al consumidor generó diversos efectos. La necesidad de su explicitación lo acercó de alguna manera al público y develó los actores que en él participan. A su vez, desde el punto de vista económico sumó incertidumbre, mientras que políticamente generó una devaluación de la palabra pública. Pero el nudo central que se rescata en la investigación, más allá de afirmar la necesidad de volver a consolidar los números públicos, reside en el proceso de democratización abierto en la discusión en torno a las estadísticas.

La obra nos enseña que recuperar las estadísticas ya no como simples números sino como objetos culturales implica pensarlas en sus múltiples dimensiones de la realidad social que también integran y construyen. La estadística no es transparente ni lineal y el abordaje histórico permite desmontar las tendencias a naturalizar e institucionalizar las cifras e indicadores. Ahora bien, esto no implica que las estadísticas deban ser fugaces y constantemente inestables. Por el contrario, necesitamos de ellas como referencias para la acción social.

La investigación muestra a los "números públicos" en su significación profunda. Es decir, en sus efectos concretos, como modelización de la realidad social, como forma de canalizar el conflicto y como herramientas políticas potentes. La obra tiene la virtud de la apertura del foco desde el cual se observan los "números públicos". Esa mirada 
no apunta hacia la validez científica metodológica sino más bien a pensar cuáles son las condiciones, mecanismos y prácticas que llevan a que se validen socialmente.

El libro invita al lector a reflexionar acerca del rol de las encuestas políticas en el marco de las democracias contemporáneas y en la tensión inherente entre opinión pública, voluntad política y representación de la ciudadanía, al punto de interrogar cómo el lazo de representación es afectado por los "números públicos". 